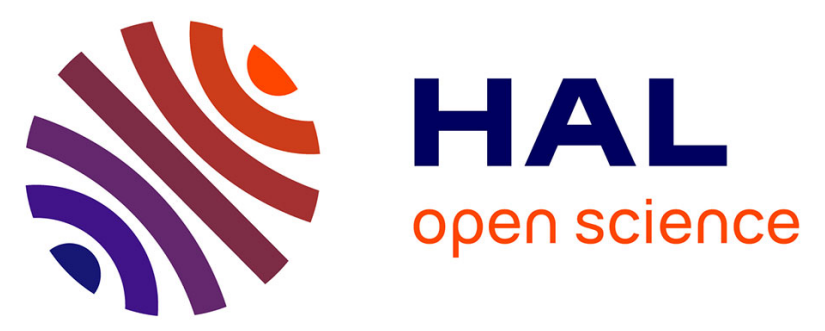

\title{
Plas'O'Soins : An Interactive ICT Platform to Support Care Planning and Coordination within Home-Based Care
}

Elyes Lamine, Rémi Bastide, Marinette Bouet, Paul Gaborit, Didier Gourc, François Marmier, Hervé Pingaud, Michel Schneider, Farouk Toumani

\section{To cite this version:}

Elyes Lamine, Rémi Bastide, Marinette Bouet, Paul Gaborit, Didier Gourc, et al.. Plas'O'Soins: An Interactive ICT Platform to Support Care Planning and Coordination within Home-Based Care. Innovation and Research in BioMedical engineering, 2019, 40 (1), pp.25-37. 10.1016/j.irbm.2018.10.015 . hal-01936639

\section{HAL Id: hal-01936639 \\ https://imt-mines-albi.hal.science/hal-01936639}

Submitted on 27 Nov 2018

HAL is a multi-disciplinary open access archive for the deposit and dissemination of scientific research documents, whether they are published or not. The documents may come from teaching and research institutions in France or abroad, or from public or private research centers.
L'archive ouverte pluridisciplinaire HAL, est destinée au dépôt et à la diffusion de documents scientifiques de niveau recherche, publiés ou non, émanant des établissements d'enseignement et de recherche français ou étrangers, des laboratoires publics ou privés. 


\title{
Plas'O'Soins: An Interactive ICT Platform to Support Care Planning and Coordination within Home-Based Care
}

\author{
E. Lamine ${ }^{\mathrm{a}, \mathrm{b}, *}$, R. Bastide $^{\mathrm{a}, \mathrm{d}}$, M. Bouet ${ }^{\mathrm{c}}$, P. Gaborit $^{\mathrm{b}}$, D. Gourc ${ }^{\mathrm{b}}$, F. Marmier $^{\mathrm{b}, \mathrm{f}}$, \\ H. Pingaud ${ }^{a, e}$, M. Schneider ${ }^{c}$, F. Toumani ${ }^{\mathrm{c}}$ \\ a Toulouse University, ISIS, Institut National Universitaire Champollion, Rue Firmin-Oulès, 81104 Castres, France \\ ${ }^{\mathrm{b}}$ Toulouse University, IMT Mines Albi, Department of Industrial Engineering, Route de Teillet, 81013 Albi Cedex 9, France \\ c Clermont Auvergne University, CNRS, LIMOS, 63170 Aubiere, France \\ d Toulouse University, CNRS, IRIT, F-31432 Toulouse Cedex 04, France \\ e Toulouse University, CNRS, LGC, F-31432 Toulouse Cedex 04, France \\ ${ }^{\mathrm{f}}$ Strasbourg University, CNRS, BETA, av. de la Forêt Noire, 67085 Strasbourg Cedex, France
}

H I G H L I G H T S

- Designing an ICT platform for supporting coordination homecare processes.

- Defining a DSL specifying care plans allowing transition towards the planning task.

- Providing a care plan verification approach based on timed automata.

- Providing an algorithm for planning the daily activities with multiple timewindows.

- Testing and validating all proposals in real conditions with the user partners.
GR A P H I C A L A B S T R A C T

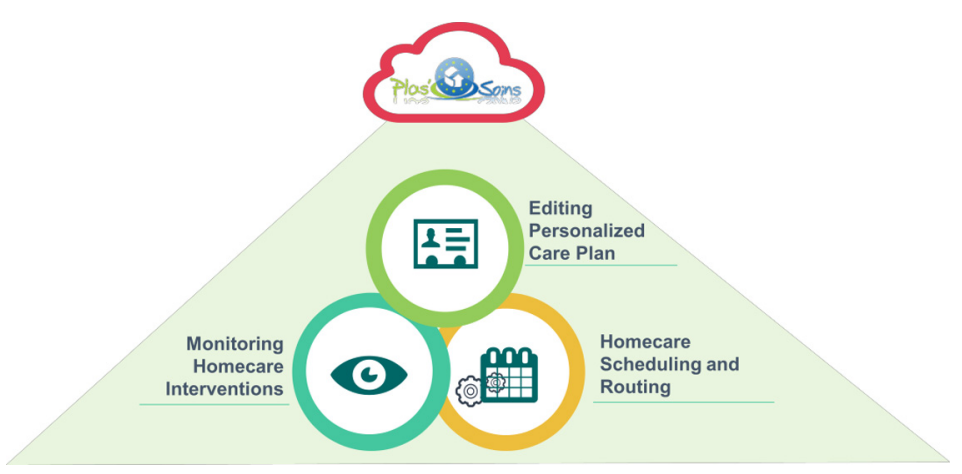

Keywords:

Homecare

Coordination

Personalized care plan

Dynamic care planning

Domain specific language

\section{A B S T R A C T}

Background: Due to the rising demand in home healthcare services in France as well as in other European countries, homecare organizations are facing challenges in terms of coordination and continuity of care. In both cases, the problem is linked to the efficiency in which care interventions are distributed and managed among the different participants involved in home care processes. Project Plas'O'Soins which was developed within the framework of the French research program TecSan, aims to address these contemporary problems by providing an interactive ICT platform to improve coordination and continuity of care within homecare organizations.

Main achievements: Plas'O'Soins, the software platform we designed, supports care specification as well as planning and monitoring of the care plans. It allows the modeling of care plans using a dedicated Domain Specific Language, the scheduling of care operations taking into account the human resources, the medical constraints and the geographical distribution of patients, and the monitoring of the execution of the operations by the care actors. This software platform enables the coordination of activities and the communication between actors and reacts to unforeseen events and produces dashboards in order to quantify the effectiveness of the processes.

\footnotetext{
* Corresponding author

E-mail addresses: elyes.lamine@univ-jfc.fr (E. Lamine), remi.bastide@irit.fr (R. Bastide), marinette.bouet@uca.fr (M. Bouet), paul.gaborit@mines-albi.fr (P. Gaborit), didier.gourc@mines-albi.fr (D. Gourc), francois.marmier@mines-albi.fr (F. Marmier), herve.pingaud@univ-jfc.fr (H. Pingaud), michel.schneider@uca.fr (M. Schneider), farouk.toumani@uca.fr (F. Toumani).
} 
Conclusion: The software platform has been deployed and used in an experimental setting by homecare partner organizations, providing valuable insights on the organizational changes required by the introduction of such an ICT solution in the actual practice of homecare.

\section{Introduction}

Over these last decades, there has been a significant demographic shift, including the aging of the population. This demographic change is accompanied by an increased proportion of fragile and elderly persons, with a correlated rise in chronic diseases (e.g. diabetes, heart failure, etc.) that require continuous monitoring and care management on a long-term basis. Faced with this evolution, hospitals become unable to meet care demands and in order to relieve their congestion, home care organizations have become increasingly common in healthcare delivery. Indeed, they ensure the transfer of an important part of patient care from hospitals to patients' homes by coordinating the activities of all the personnel involved in the patient's care process.

Within the home care environment, care coordination is considered as both crucial and timely for the efficient delivery of provided care services. Home care activities form a collaborative process, which is a set of potentially linked set of interventions regarding social care, health care, or both [1]. In this context, an intervention describes a visit at the patient's home, undertaken by a medical or paramedical staff on a specified time slot. In other words, an intervention is composed of several medical or technical acts performed by the staff on a single visit. Currently, home care organizations are facing many management hurdles mainly in terms of coordination, which manifest at two levels [2]: (1) The interventions level: where different social and healthcare providers have to organize the delivery of home care activities and information exchanges regarding carried out interventions. (2) The transitions over time level: where the stakeholders must ensure continuity and consistency of provided care between different episodes of care transition and across the full spectrum of patient's care, particularly when moving from one care institution to another.

The coordination of home-based interventions at the first level is generally focused on the follow-up of proper realization of patient care plans. The second level of coordination is mainly related to the continuity of care over time through the integration, collaboration and sharing of information between different providers. The coordination at this level simply consists of organizational shifting of care responsibilities and the transfer of current patient state condition and eventually the enactment of care history.

Referring to the above-mentioned levels the focus of Plas'O'Soins project is on the first level of coordination since we consider it to be a fundamental step for home-care management. Indeed, this level of care coordination focuses on organizing staff and other resources to carry out the required cares while managing the exchange of necessary information among the different actors involved in home-care processes. Within Plas'O'Soins project, we attempt to develop an ICT platform for better managing the coordination of care and services to patients at home, a better flow of information related to patients and a better monitoring of home care in a context of improved quality of services and control of public health expenditure. We recommend an explicit specification of personalized care plans in order to deduce the scheduling of all the visits. The main processes are thus: Editing personalized care plan, Home-care scheduling and routing, and Monitoring home-care interventions.
The paper is structured in three main parts. In the first one, we present a state of the art of the use of ICT methods and techniques for home care and we point out the challenges for this. The second part is focused on the presentation of the results obtained within the Plas'O'Soins project, in particular the design of the three main processes and the implementation of the ICT platform. In the third part, we discuss the obtained results and we put them into perspective with ongoing work. Finally, we provide a conclusion and future outlook.

\section{State of the art}

The interest of using information and communication technologies (ICT) to support home care has long been investigated through numerous studies, both in academic and professional circles. This work resulted in recommendations, prototypes and commercialized software platforms. We first present a global vision, then we focus on points of interest related to the Plas'O'Soins project.

\subsection{Global overview of ICT in home healthcare}

First attempts to use ICT for home care are related to telemedicine. Telemedicine started early 1990s with the advent of audio and video technologies. Telemedicine can provide valuable help for home care [3]. Its simplest form is telenursing, which allows remote consultation or remote monitoring. Remote monitoring involves various devices used by the patient at home to collect and transmit medical data. These technologies are used to alleviate or even avoid some of the home visits. Telemedicine for home care has been tested with some success Darkins et al. [4], Kamei [5]. Cost reduction is effective, but social impact remains to be assessed precisely. Telemedicine benefits now from the accelerated development of mobile devices and connected objects.

Numerous studies have been devoted to the development of ICT platforms integrating some or all of the functions for home care. The principles used are varied: ECA rules approach [6], Ethnographic approach [7], Ontological approach [8,9], Multiagent approach $[10,11]$, Process approach [12,13]. Initiatives are academic and professional. Numerous commercialized software have been proposed in the Anglo-American context (ConsumerAffairs ${ }^{1}$ ) or in the Francophone context (we can cite $\operatorname{Arcan}^{2}$ or Medlink ${ }^{3}$ ). The functionalities offered by this software can relate to financial management, patient management, remote access via mobile devices, sometimes scheduling and routing home visits. Such software is generally expensive. A precise assessment of the use of these prototypes and systems in real conditions remains to be established.

\subsection{Care plan modeling and verification}

One of the main documents in home care is the care plan which is the planned list of care acts to be performed for a patient [14]. The care concern acts and treatments to which are associated a

\footnotetext{
Compare Reviews for Best Home Health Care Software http://www. consumeraffairs.com/online/home-health-care-software/.

2 AtHome software http://www.arcan.fr/logiciel-suivi-soins-a-domicile.html.

3 MedLink product http://www.med-link.org/.
} 
frequency and schedules [15]. This is a reference document for all actors. To model and exploit the information contained in care plans is thus extremely important if we wish to favor information exchanges between the different actors implied in home care and to improve the continuity of the care. There are medical ontologies (CIM10, CCAM, ...) or standards such as HL7 on which the definition of a care plan can be based. But it is also necessary to define the operational part (resources, duration, frequency) of the acts to be carried out. In $[16,17]$, the interest to design standardized care plans and to define a generic framework to improve the practice of home care is underlined. Hägglund et al. [18] goes farther by highlighting the necessary matching between the standards of medical representation of knowledge and the systems of exchange of information. Another problem is the necessity to verify the validity of the care plan before making the planning of tours. We also notice a lack of IT support in the checking of the care plan during its editing. Finally, it also seems important to contextualize or personalize the care plan, which we materialized by a domain-specific language (DSL) in Plas'O'Soins project.

\subsection{Homecare scheduling}

Main researches in the field of home health care, concerning routing and scheduling problems which are an instance of VRP problems, started around 2000 with, for example, the works of Hindle et al. $[19,20]$ concerning resource allocation and travel cost approximations.

Ernst et al. [21] proposes an important annotated bibliography synthesis on computational methods for rostering and personnel scheduling. The authors classify articles, more than 700 references, according to the type of problem addressed, the domain of application and the methods used. In addition, Rinder et al. [22] present a systematic literature review of the application of industrial engineering methods in healthcare scheduling. Techniques and methods that have been used in past works are multiple and cover a huge part of industrial engineering methods and Operation Research methods. They can be decomposed in exact methods (Linear Programming, Tree Search Space, Branch-and-Bound and Constraint Programming), heuristics methods and metaheuristics methods (like Variable Neighborhood Search, Simulated Annealing, Evolutionary Algorithm). Moyaux et al. [23], Burke et al. [24] and Meisels and Schaerf [25] develop an approach based on a constraint satisfaction technique; Beddoe and Petrovic [26] use a case based reasoning approach; Chen and Yeung [27] and Yeung [28] propose an expert system; Bachouch [29] uses heuristics and metaheuristics techniques; tabu search; Akjiratikarl et al. [30] propose an original approach using an algorithm of Particle Swarm Optimization (PSO) to build the schedule of the home care actors. This algorithm combines a global exploration of the space of the solutions and a procedure of local search to refine the solution by an analysis of the neighborhood.

In the Plas'O'Soins project, we tackle a specific problem of routing and scheduling which is called Vehicle Routing Problem with Multiple Time Windows (VRPMTW). This problem is derived from the VRPTW problem which is an extension of the VRP, where a specific constraint is added, requiring the start of service for each customer within a time window. Vidal et al. [31] propose an extensive state-of-the-art of methods used to solve several routing and scheduling problems derived from VRPTW. To our knowledge, the VRPMTW has received relatively little attention in the operations research literature, it has only been investigated by Favaretto et al. [32] in 2007. In the context of Home Health Care (HHC), there was no work dealing with VRPMTW for HHC, no results had been produced before the project started.

Based on several studies [33-37], Fikar and Hirsch [38] extend the literature review of HHC routing and scheduling papers. Their review is structured in two classes of works: first those related to single-period home health care problems and then those concerning multi-period home health care problems. Based on this categorization, Fikar and Hirsch [38] propose a systematic review of objectives and constraints modeled in HHC routing and scheduling problems. Objectives identified in this literature review enhance the set of objectives classically listed in VRP problems. The objectives mentioned in HHC works concern several dimensions: travel time, travel cost, travel distance, wait time, overtime, preference, number of nurses, soft constraint violations, fairness (workload balance), number of tasks, patient preferences, staff preferences. Additionally, a set of constraints was identified by authors in HHC works, this list is composed of: time windows, skill requirements, working time regulations, breaks, precedence, synchronization, workload balance, uncertainty. None of the works identified implements simultaneously all the items listed.

To manage the optimization process, most of the authors develop a mono objective approach which can be the consolidation of several elementary objectives in a consolidated objective function. Some other works propose a bi-objective approach, as for instance Braekers et al. [37]. In the Plas'O'Soins project, we have chosen to implement a two stage approach combining multi objective in a first step and then an aggregated objective to select the best solutions.

\subsection{Monitoring homecare interventions}

Monitoring homecare interventions consists of keeping track on the implementation of the planned interventions in order to ensure the proper execution of the prescribed patient care plans and to alert the coordinator in the event of unforeseen problems. For this reason, it is essential to have relevant situational knowledge about the field by obtaining timely feedback which allows the coordinator to make the right decisions at the right time.

Mobile devices, such as smartphones, tablets and smartwatchs, are recognized as being essential for receiving immediate feedback, in the homecare domain particularly through continuous daily patient monitoring and checking compliance with self-management programs. Nowadays, many promising projects exist based on the use of mobile devices and allowing the remote monitoring of patients' basic vital signs and to generate alerts in case of anomaly $[39,40]$. However, despite all the benefits that can arise from the use of mobile device in healthcare domain, there are still many challenges that must be overcome, and among which stand out user attitudes, technology acceptance and threats to confidentiality and privacy [3]. To this end, a particular attention was paid, within the Plas'O'Soins project, to the acceptability of the proposed solutions and to the security and confidentiality of the storage and exchange of data.

The state of the art at the beginning of the Plas'O'Soins project can be summarized as follows: We observe a good understanding of the different features of coordination and communication, but it remains the need to evaluate the proposals in real contexts with a sufficient variety of situations. Scheduling and routing solutions are too often disconnected from other functions and it exists a strong requirement to adapt them to the conditions actually encountered by the home care structures, taking into account the planning dynamics and the uncertainties of operations. We note a lack of a precise description of the care to be carried out with consequent inability to check for inconsistencies and make the linkage with scheduling and routing; It remains the necessity to fully integrate the different processes, going from patient admission to patient exit and taking into account care specification, scheduling and routing, coordination of actors. 


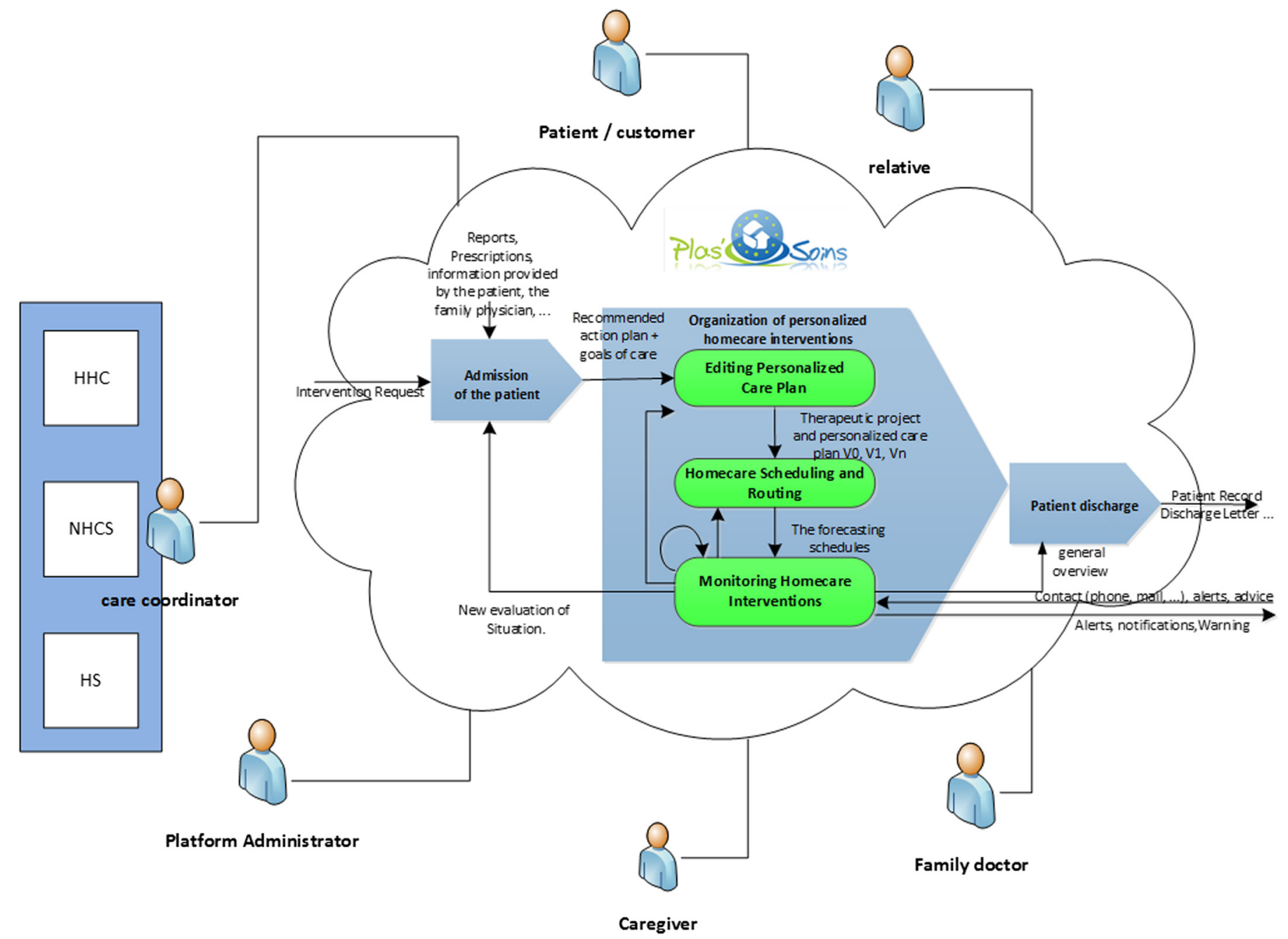

Fig. 1. Overview on the functional architecture of the Plas'O'Soins Platform.

\section{Main achievements}

\subsection{Overview on the functional architecture of the platform}

The diagram in Fig. 1 provides a broad overview of the functional architecture of the platform. It is process oriented. The three main processes constitute the backbone around which other processes such as the admission process or the discharge process are organized: (1) Editing Personalized Care Plan: It is based on a Domain Specific Language (DSL) approach for modeling a customized care plan according to the patient's profile; (2) Homecare Scheduling and Routing: It is about the finding of a weekly assignment of caregivers to homecare interventions according to patients' care plans and generating tours taking into account many specific constraints; (3) Monitoring Homecare Interventions: It is focused on the follow-up of proper realization of patient care plans.

These components are described more specifically in the following paragraphs.

This diagram also shows the different types of actors and their interactions with the processes.

\subsection{Care plan modeling}

All the medical and social activities delivered for a given patient according to certain frequencies are scheduled in a home care plan. Hence, the notion of a care plan is a key concept in home care area. In the Plas'O'Soins project, we are interested by the problems underlying the design and management of the home care plans to bring some comfort to the medical coordinator, avoid the collision when planning activities or to ensure the feasibility of the home care plan. After a domain analysis performed with end-users, we proposed to describe home care domain concepts through UML class diagrams according the three visions (expected, planned and performed) of the care plan (Fig. 2). Having an appropriate external representation of the care plan is appeared crucial to assist as much as possible the medical coordinator in the design of individual care plans. That's why we propose a DSL based approach, tailored to express home care plans using abstractions highlighted in the UML analysis [41].

The DSL consists of all the objects that can appear in a care plan and operations that can be made on these objects. The activity (act) is the central concept. It must be performed by an actor of a certain type (physician, nurse, nurse auxiliary, liberal helper ...) with some qualifications. The activity may also involve material resources and consumables that the system must be able to manage. The set of activities is known and stored in a knowledge base. Each activity is associated with the actor type (nurse, nurse auxiliary ...) and any consumables. An indicative duration of the acts (e.g. average of the durations already observed) is also suggested. All the data are stored in the knowledge base.

An intervention is a grouping of acts which can take place in the same time slot and which can be carried out by the same actor. Thanks to this concept, we switch from the medical vision of the care plan (patient oriented) to the operational plan of the care 


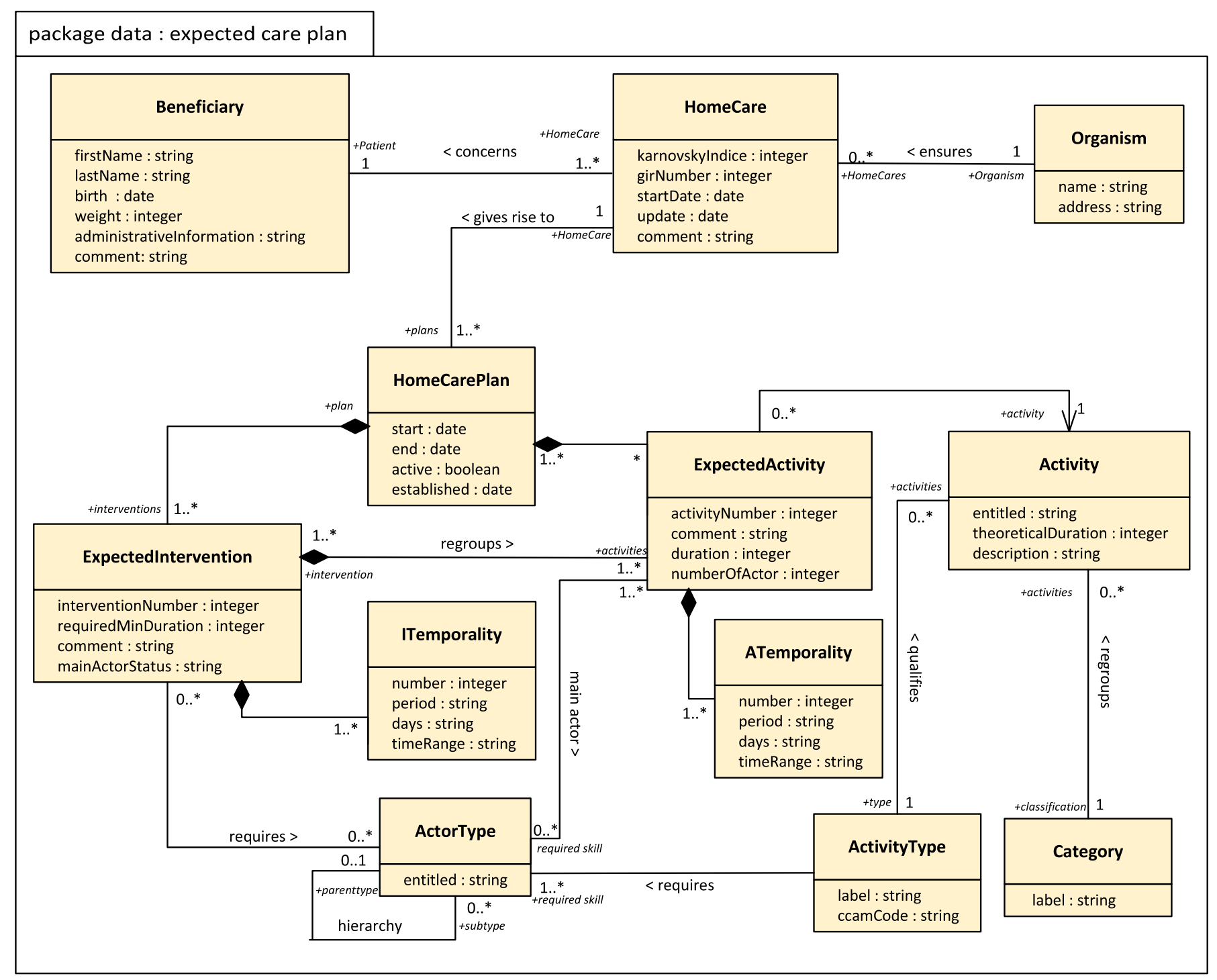

Fig. 2. One of our class diagrams: prescribed view of the care plan.

plan (actor oriented). There are always several possibilities for distributing the acts into interventions and the search for the best solution is not trivial. Our system suggests interventions, which the coordinator may rearrange as he pleases and finalize them before moving on to the planning stage. The rules used to infer these interventions are as follows: the acts involved in the composition have compatible time slots and can be performed by the same type of actor.

Finally, an intervention is defined by the acts that compose it (with possible successional constraints), a time slot, a duration (sum of the durations of the acts forming part of its composition), a type of actor (possibly an actor). The planning module will be responsible, for each occurrence of an intervention, to set the start time and end time and assign it to a tour and an actor.

To assist the coordinator, the care plan may be displayed according to a developed form (agenda form) (Fig. 3) and / or according to a condensed form (Fig. 4) knowing that the developed form is deduced automatically from the condensed form. The condensed form is closer to common medical use (semi-natural language) and easier to communicate.

The condensed form is used by the coordinator to specify the care plan. For each act, it indicates its time slot and frequency of repetition (every morning - every Monday, Wednesday and Friday at $18 \mathrm{~h}$ ), certain constraints for actors (type, status - liberal, not liberal -, preassigned for the patient).

Our DSL has been designed to offer a variety of possibilities to specify the range and frequency of an act. It also makes it possible to indicate the particular cases and exceptions. Temporal modalities are formalized as a quadruplet (Days, Time ranges, Period, Duration) where (1) Period: specifies the time period during which the activity is defined, (2) Days: indicates the days within a period in which an activity must take place, (3) Time: ranges indicates the time slots in which the activity can occur and (4) Duration: gives theoretical duration which corresponds to the average of already observed durations.

Days and Time ranges attributes can take several patterns to correspond to the different possibilities encountered in the medical world (e.g. on morning, on Mondays...) and exceptions clauses are introduced via the keyword "except" (e.g. every day except public holidays). For controlling the specification, we have proposed a language expressed in BNF form which enables regular or irregular repetitions of an act within some period [42].

The DSL concepts allow us to describe the home care domain concepts through the UML class diagrams and can handle temporal irregularities. Through the condensed or developed forms, it is not obvious at first glance whether the plan care contains incon- 


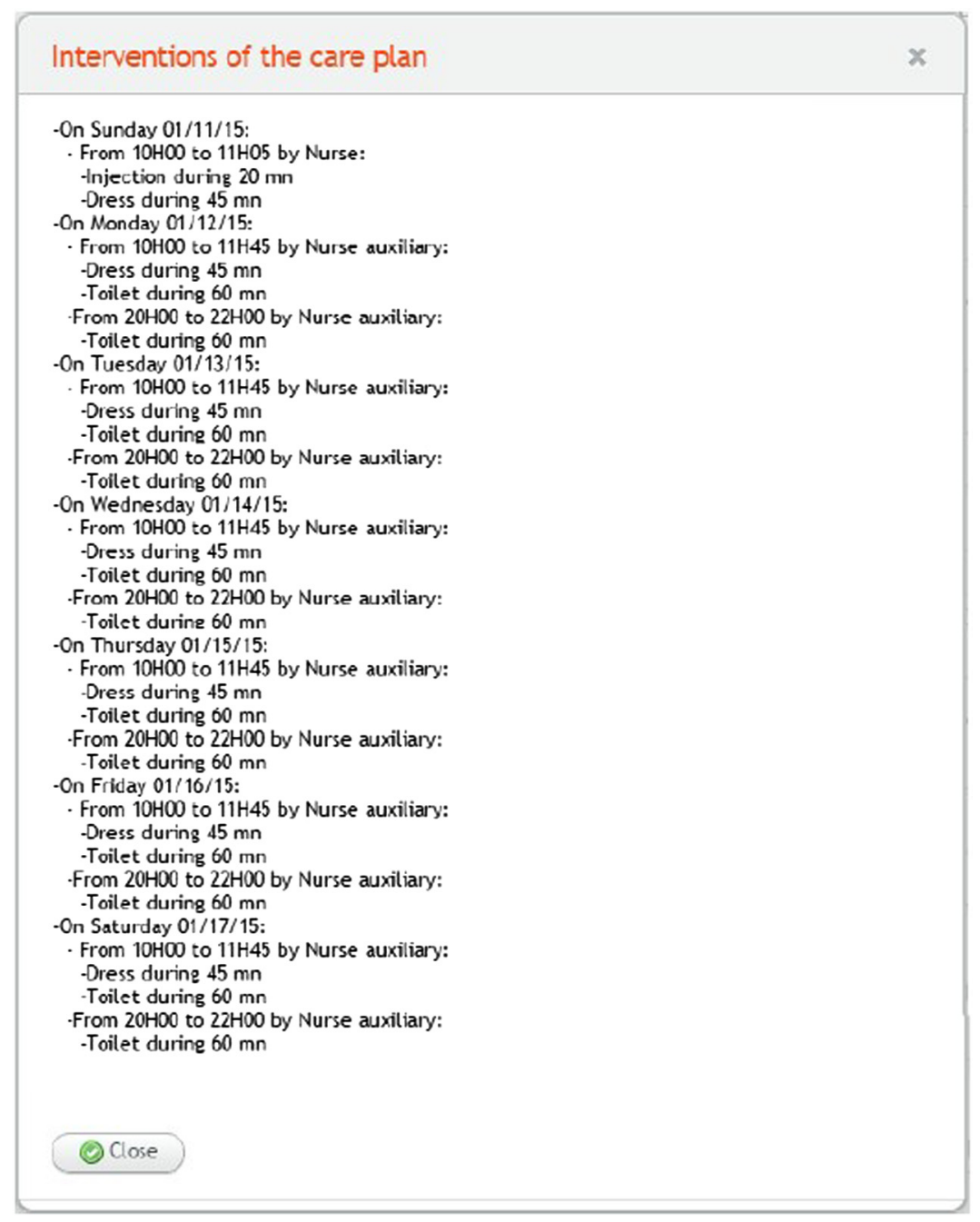

Fig. 3. Specification of a care plan: agenda form.

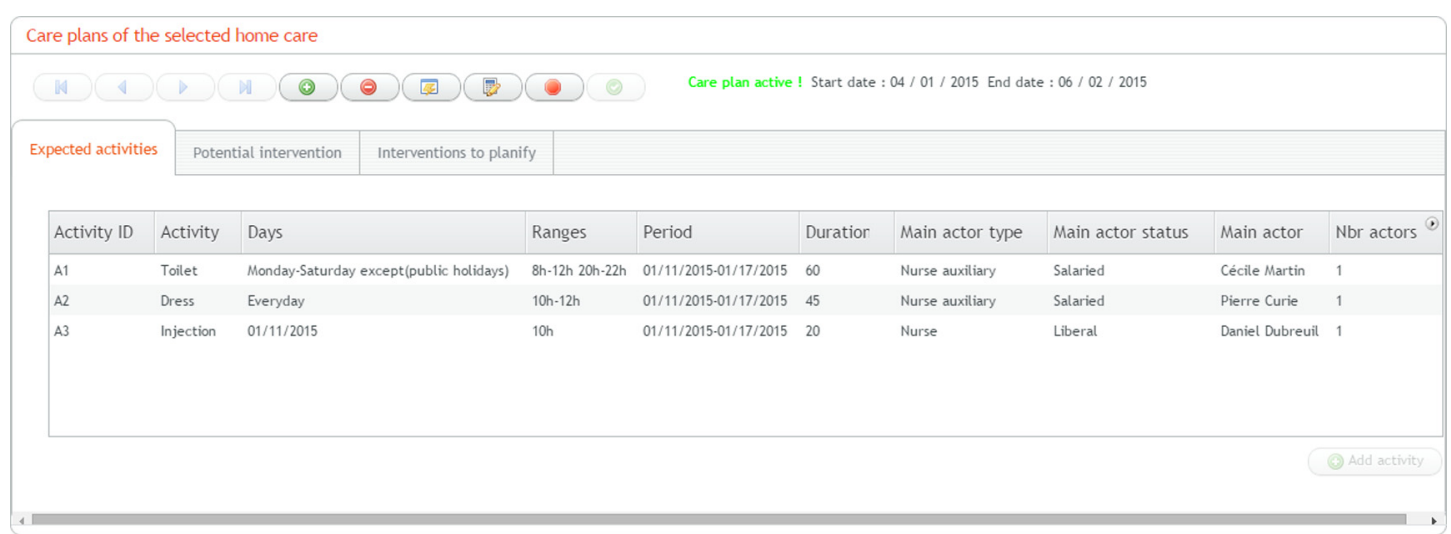

Fig. 4. Specification of a care plan: condensed form.

sistencies or time impossibilities. In the Fig. 5, a problem arises on Sunday, January 11th, 2015 for the act Parenteral nutrition. So the care plan is not realizable. This is why, we propose a tool (cf. next section) to verify care plan before starting the planning step.

\subsection{Care plan verification}

It is important to provide tools to assist as much as possible the medical coordinator not only in the design of individual care plans, but also in the automated support for verification of the plan and monitoring of its execution. Although the condensed form of care plans allows more sophisticated reasoning than the developed form, a more formal representation is needed to meet the needs for control of the care plan. As temporal constraints play a crucial role in home cares, the proposed formalization is based on existing theory and tools in the field of timed automata $[43,44]$. Obviously, this projection in the timed automaton field is completely transparent to the coordinator. He continues to design the care plan 


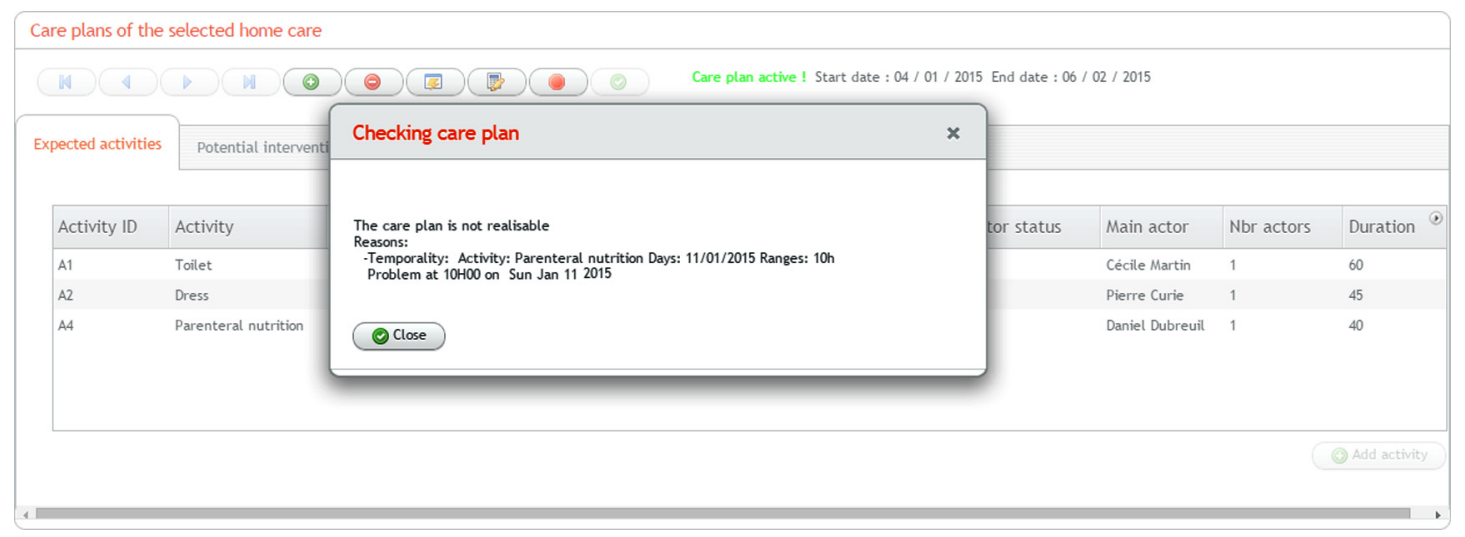

Fig. 5. Example of a non-realizable care plan.

as explained in the previous section. From there, the system automatically transforms the care plan into a timed automaton and indicates whether the care plan is feasible or not. More generally, this transformation is indispensable to perform any kind of verification and monitoring of the home care plan. In the field of automata, the notion of a medical or paramedical act is assimilated to an activity. Therefore, we only use this designation in the rest of this section.

Our approach is based on two steps:

1. Definition of the activity automaton: The objective of this step is to map each activity into an activity automaton. The problem is simple when the temporality of an activity is expressed through a single pattern. Each pattern defines, through its duration and period, a pattern automaton which becomes the activity automaton. This case is illustrated in Fig. 6 for the two activities. The problem is more complex when the temporality of the activity uses several patterns. The resulted pattern automata must be assembled together to generate the activity automaton according to the classical intersection operation [43]. If an irregularity is indicated at the level of a temporality, the corresponding exception is translated into new transitions and guards on the pattern automaton. Explanations and examples illustrating these cases can be found in [45]. The resulting timed automaton recognizes all possible timed words corresponding to all the possible correct schedules of the activity.

2. Definition of the care plan automaton: The construction of the care plan automaton from the activity automata is automatic. It uses a specific personalized composition operator based on an asynchronous product on some states, on a synchronization product on waiting states and on blocking operations in the execution states. It must also guarantee that a single activity is executed at a precise time $t$. Most of the existing works considered timed automata without duration. In our approach, we handle the problem of duration by extending the basic model of timed automata with the notion of execution state and by redefining the composition operator. This extension does not increase the expressive power of the basic automata, and hence, does not impact their computational properties. So, a care plan automaton describes all the possible legal schedules of a home care plan for a specific patient (Fig. 6).

Once the care plan automaton is generated, we use the UPPAAL Model Checker to test the model obtained. In our context, satisfying properties allow us not only to check the feasibility of a care plan (the classical emptiness problem [46]), but also to compute automatically interventions (grouping of activities of home care plan to minimize the total number of interventions and to reduce the cost of home care). Further details may be found in [45]. The proposed system (DSL + timed automata + model checking) is used to move from a patient oriented process (a medical view of a patient-specific plan of care) to a operational process (estimated interventions) of the care plan.

\subsection{Homecare scheduling and routing}

In home health care (HHC), planners have to schedule interventions identified in care plans, which are associated to patients. Each patient have his/her own care plan which is modeled as presented above in section 3.2. So, a home care structure have to organize operations for several patients/clients. Planners assign actors (nurse, nurse auxiliary, ...) to patients, schedule working times and identify arrival times of nurses to each patient. For this, travel routes have to be identified and evaluated.

Several requirements, expressed by stakeholders, have to be integrated in the scheduling procedure, such as matching nurses' skill and patients' wishes or medical requirements [38]. In this study, we have classified requirements and hard constraints according to three points of view: nurse oriented, patient oriented or, structure and tour oriented. Some examples of constraints we have modeled for each point of view are presented below. Concerning nurses' wishes, the assignment have to respect contractual and legal working time of each nurse, and to limit waiting times i.e. no interruptions during the tour. Individual preferences of each worker can be used to organize the planning. For patient, constraints modeled are: respect of visiting time windows given by the patient (it can be considered one or several possible time window for a given visit), respect of the time between two or more visits on the same day for a specific patient. Home health care structure constraints are rules which hold for the entire organization, they are often based on legal regulations constraints as: respecting workers' legal worktime by day, by week, by month (e.g. minimum/maximum hours of work by day, by week, by month), respecting skills and qualification required to realize the intervention, all the interventions identified in the care plan have to be planned for the expected day which are expressed in the temporal modalities of the patient' care plan (see 3.2), minimizing the travel trip (duration and distance).

In the project Plas'O'Soins, we focus on a daily home care routing and scheduling problem. One of the originalities of this work concerns multi time window requirements' expression. In this way, the optimization process allows to take into account patients' preferences expressed with multiple time windows. Patients can allow several time-windows on a day for nurses' visit. For example a patient can be visited by an actor if he respects the next constraints: 


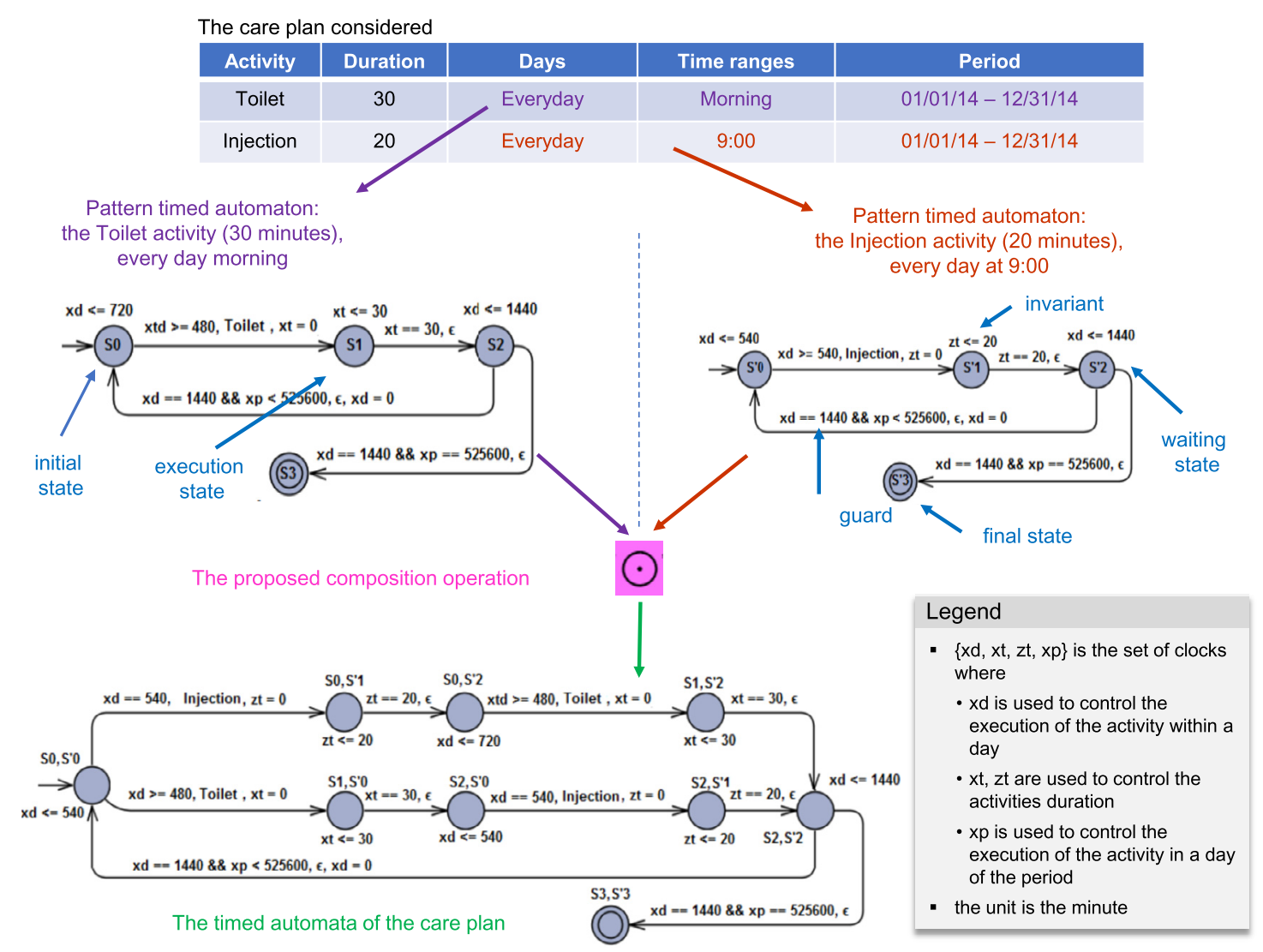

Fig. 6. Process of definition of the care plan automaton.

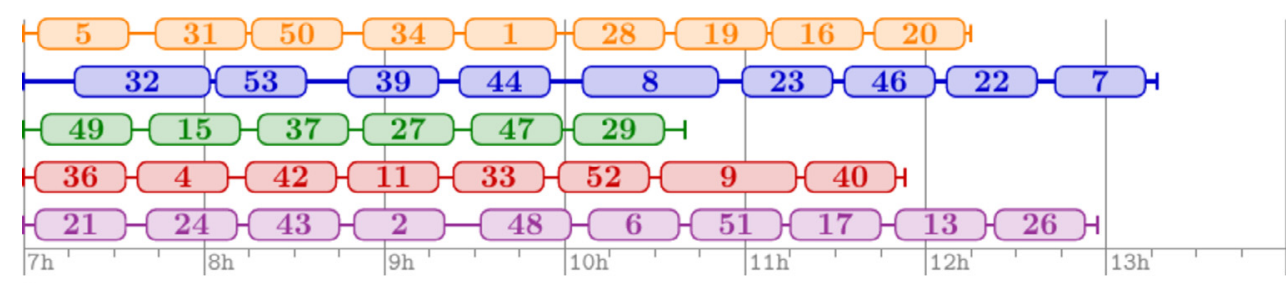

(a) generated by human expertise

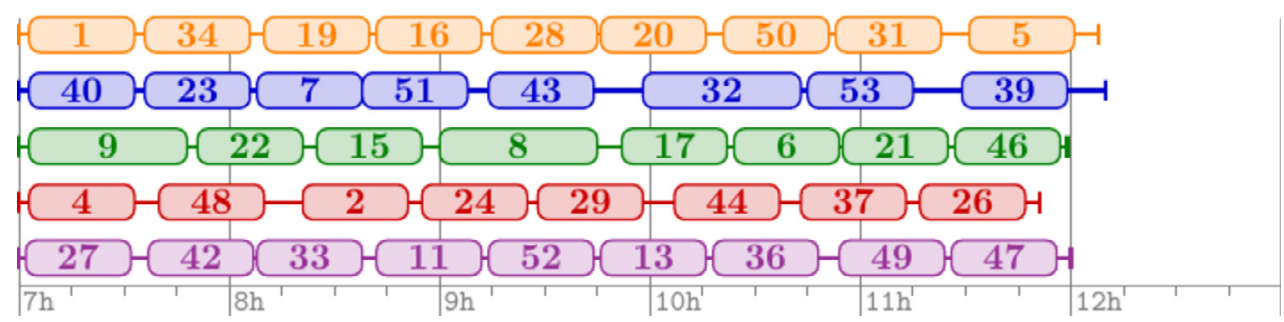

(b) generated by our automatic approach

Fig. 7. Examples of five tours' planning.

(between 8 h 30 and 9 h 30) or (between 11 h and 12 h). These time-slots are modeled in the care plan during the first visit of the HHC coordinator at patient home.

Based on these constraints and requirements, the optimizer module have to generate solutions and give the best ones. For this, we have developed a specific set of objectives according to the strategy of the HHC' partners of the project. In this project, the objectives have been categorized in two classes of criteria to eval- uate each solution generated. The first class is composed of three criteria that are the most important weight in the evaluation process: maximizing the patients' preferences which is expressed with time windows respect $\left(c_{1}\right)$. Time windows for each intervention are defined in the patients' care plan; minimizing the planned tour overtime $\left(c_{2}\right)$ for respecting nurses' work time. This objective focused on both minimizing the total work time for nurses and aims to limit the overtime; maximizing the respect of time interval be- 

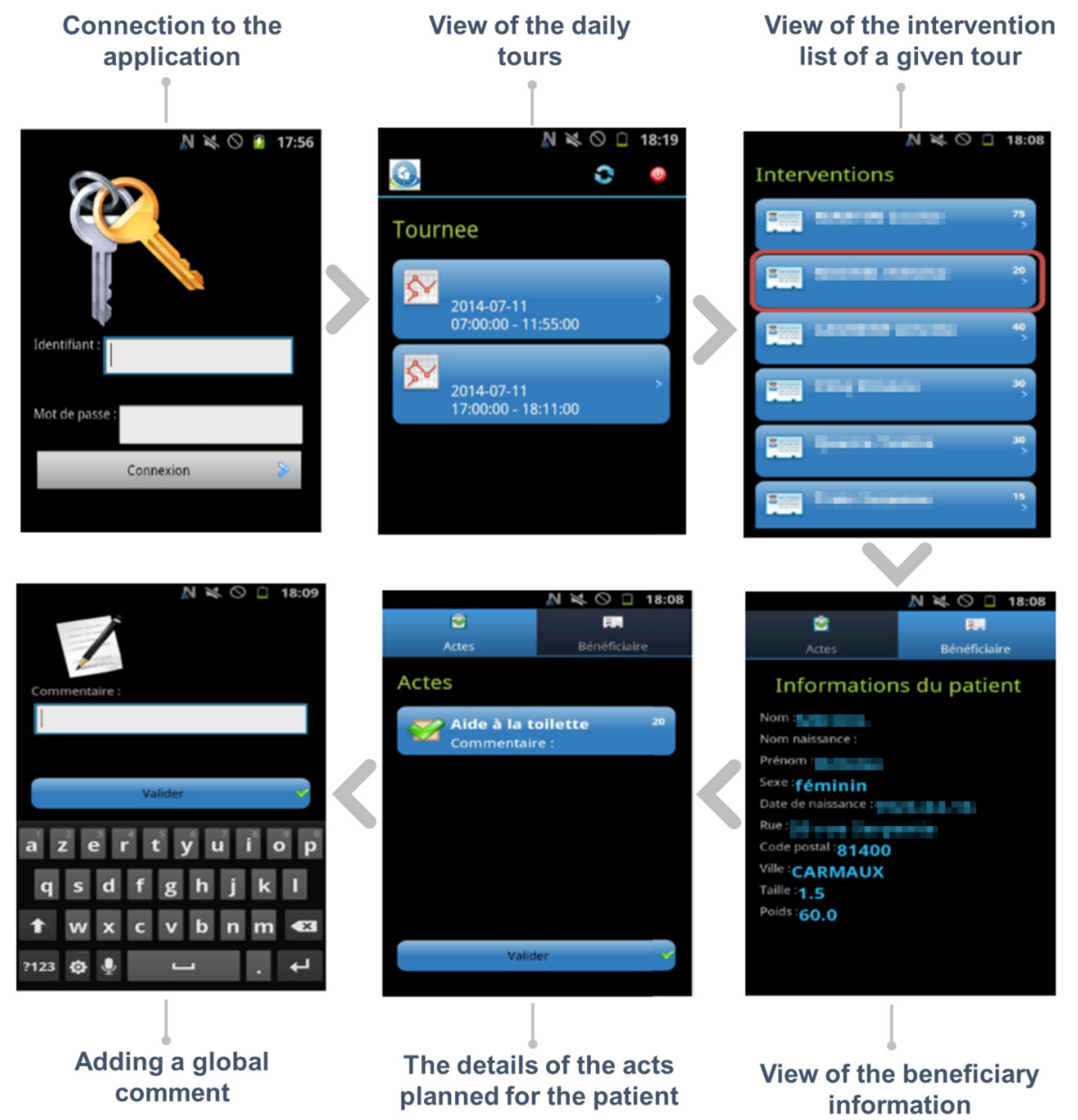

View of the beneficiary information

Fig. 8. An overview of the mobile user interface.

tween two visits $\left(c_{3}\right)$. These criteria aim to validate the realism of the solution, they correspond to constraints to comply with.

The second class of criteria concerns attributes that have to be optimized: travel time $\left(c_{4}\right)$; maximizing overtime equilibrium $\left(c_{5}\right)$. These criteria aim to minimize the difference between the longest service and the shortest service times among the workers; hardness equilibrium $\left(c_{6}\right)$. These last three criteria are aggregated with a linear function.

The solution adopted to generate the tours taking into account those specific requirements and constraints consist in a metaheuristic approach based on tabu search technique associated with neighborhoods generation technique to explore solutions [47]. In the proposed approach, three types of neighborhoods generation have been introduced: shift intervention, swap intervention, OrOpt insertion.

\subsection{Monitoring Homecare Interventions}

As shown in Fig. 8, a specific application has been developed on Android Smartphones to follow-up the proper implementation of planned visits. It allows to visualize the daily Scheduled tours and the list of patients in the order of visit with, for each one, the surname, the first name and the estimated duration of the intervention. When opening the application, an identifier and a password are required to access the information related to the worker. This application also allows to see the details of the acts planned for each patient and to validate their good realization. A global comment for the intervention could be entered as well. The information accessible from the application is stored on the smartphone in a database encrypted with the user's password. To send and/or retrieve the information from the server, it is then necessary to perform a synchronization by clicking on the button dedicated to this function. To do this, it is necessary to have a connection to the Internet network. This synchronization of the exchanged data with the server is made via PHP and stored SQL procedures.

\subsection{Software architecture and $\mathrm{HCI}$}

The proposed solution within Plas'O'Soins project is a software platform designed following the principles advocated by SOA (Service Oriented Architecture), and including mobile and locationaware devices adapted to the practice of different stakeholders. This platform is based on a model-based architecture (Model Driven Engineering, MDE), and includes in particular the definition of a domain-specific language (DSL) designed after a detailed analysis of the activity of a home care manager, and the development of specifically designed scheduling algorithms.

With regard to the implementation of this platform, the software architecture is made of several components, as depicted in Fig. 9. The server is installed on an Ubuntu operating system. All data is stored in a MySQL database. A participatory designed approach was used to guide the design of all these Human-computer Interaction $(\mathrm{HCl})$ and the choice of interaction devices. By associating users with the development of systems, it was possible to study the most appropriate forms of interaction. The coordinator interface is a web-based interface developed in Java using Java Persistence API and Tomcat. 


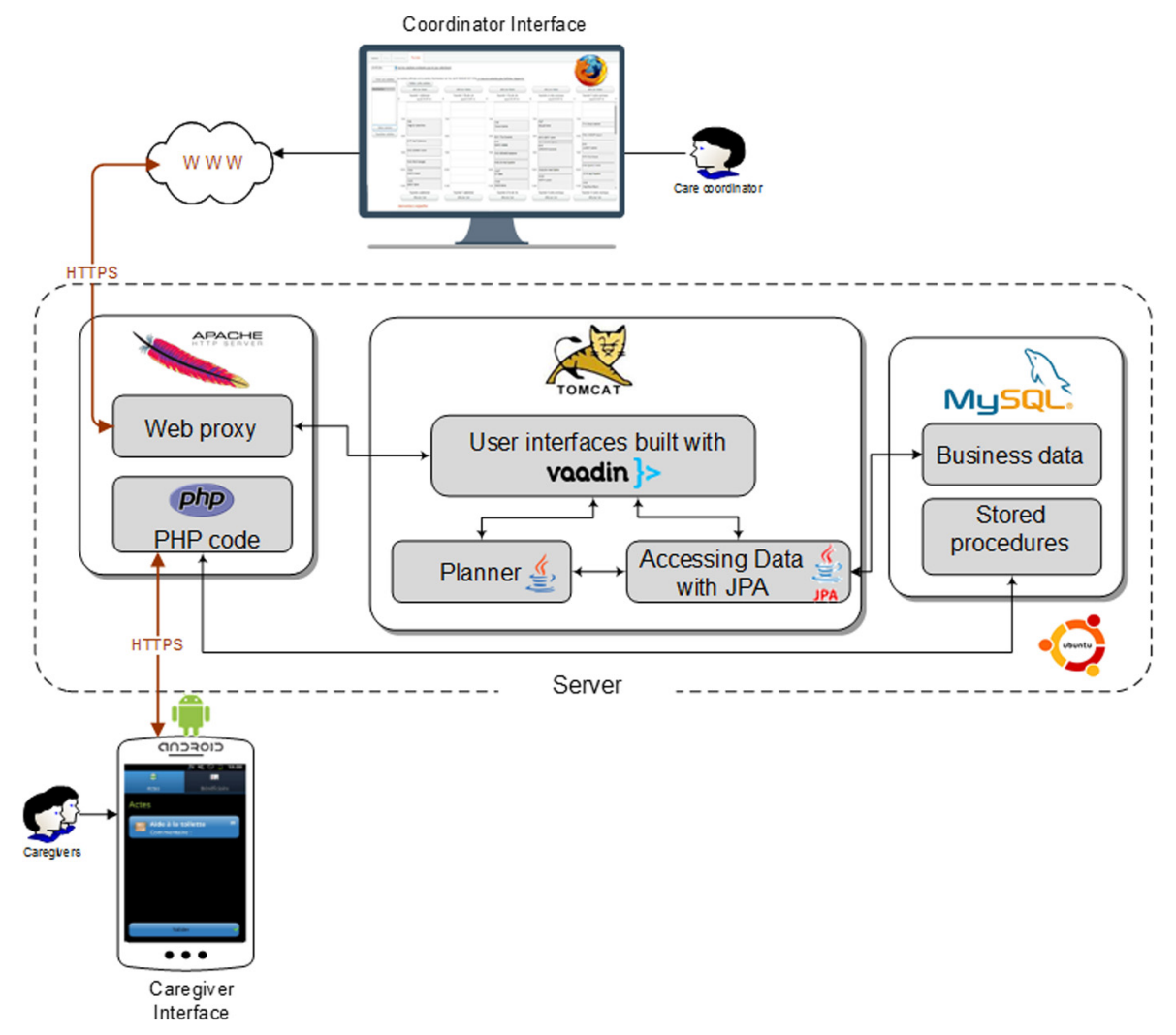

Fig. 9. Software architecture.

This $\mathrm{HCl}$ has been designed to allow the coordinator to interact with the solutions generated according to his needs. It is thus possible for him to make the necessary corrections. He will be able to move the interventions from one tour to another, or to modify their scheduling within a tour and to assign a specific caregiver to a tour.

To implement this coordinator interface, we used Vaadin framework that allows to quickly generate aesthetic and ergonomic web applications using only Java code that is transformed and then generates the HTML pages.

The data transportation between the server and the coordination browser or smartphone application is based on the HTTPs protocol and goes through a frontal Apache server.

\subsection{Experimentation}

The aim of the experiment was to validate the technical architecture of the platform, the operational use of its software modules and the staff acceptability. The experiments have been conducted with the CARMI (a regional social security insurance in the south west of France). Several coordinators and actors of the care activities were mobilized and specifically 5 Caregivers and 1.5 nurses. The study covered the cares of 55 patients. Depending of their health, patients received from 1 to 2 visits per day, 2 to 7 days per week. These interventions were done, in the morning ( 5 tours from 7:00 am to 12:00 am), in the afternoon (1 tour from 2:00 pm to 5:00 pm) and in the evening (4 tours from 5:00 pm to 7:20 pm).

The protocol to test the platform was established over a three weeks period. The first week was focused on the preparation. During this week the Plas'O'Soins consortium ensured the input of the initial information necessary for the experimentation in the databases. Necessary precautions have been taken to ensure the conformity of the software and devices with the regulations, and particularly concerning the storage of personal data and the host- ing of health data. Then a training was provided to the staff for the use of hardware and software modules.

The second week was focused on the experiment itself. The platform being a research prototype, it was necessary to use both systems in parallel: usual operation and operation on the basis of Plas'O'Soins. This replication of the work was achieved by the staff of the CARMI.

Finally, the third week was focused on the debriefing and on the analysis of the experiments. A survey was given to each participant to collect their qualitative perceptions and assessments of the platform and its modules.

Regarding the Interface for entering care plans, the functionalities offered corresponded to the needs expressed initially. The specification of the temporal constraints of the acts in a condensed form was considered to be rather appropriate. The organization of the dialog to capture these temporal constraints appeared as being adapted and valuable.

Regarding the Planning Software Module. This module, devoted to the staff in charge of coordinating the patient care, defined the patient care plans but also established a schedule of medical and paramedical tours. Figs. 7a and 7b illustrate a five tours' planning respectively done by human expertise and by the approach developed in this project. Based on this example, which is an extract from the experiments that have been carried on during the project, the gain obtained are presented in Table 1 . These results are promising and demonstrate the value of this approach the value in comparison with a purely human approach. Due to complexity and hardness of the constraints expressed, this approach is totally adapted because it is able to explore numerous solutions which can be based on a possible solution which respect a set of identified constraints to obtain new interesting ones. However, in some cases manual adaptations are required because it is impossible to take all the human rules used for generating the planning into account. 
Table 1

Comparison of the manual planning and the Plas'O'Soins solution (values in minutes).

\begin{tabular}{llll}
\hline Criteria & $\begin{array}{l}\text { Manual } \\
\text { (see Fig. 7a) }\end{array}$ & $\begin{array}{l}\text { Plas'O'Soins } \\
\text { (see Fig. 7b) }\end{array}$ & Gain (\%) \\
\hline$c_{1}$ & 145 & 1 & $99 \%$ \\
$c_{2}$ & 306 & 172 & $43 \%$ \\
$c_{3}$ & 68 & fully respect & $100 \%$ \\
$c_{4}$ & 476 & 362 & $24 \%$ \\
\hline
\end{tabular}

The experimentation has showed the difficulty of fully automatized planning generation. At the end, adjustments were necessary through the proposed interface. The debriefing phase with care coordinators allowed to identify several root causes of modifications: unexpected intervention requiring two care workers, a care worker has an exceptional family constraint, unavailability of an equipment or supplies, etc. So, this module should therefore be considered as a planning aid.

Regarding the software module for the consultation of interventions and the capture of achievements on smartphones, this one was intended for the medical and paramedical staff of CARMI, responsible for providing patient care. This module was used on mobile devices allowing each participant to consult the detailed agenda of the tours. Its handling did not pose any difficulties. The increase of available information compared to the current way of working was considered as being very useful. In the same way, users asked if information about patients could also be added.

\section{Discussion}

In this section, for each of the contributing points of the project, we recall its context, we discuss how it evolved with research work that took place later (after the end of the project) and we reposition the perspectives that remain open.

\subsection{Modeling and verifying the Home Care Plan}

The model we have proposed is one of the originalities of the project. It allows to express the temporal and organizational constraints of the care. It allows the use of timed automata to check the consistency of a care plan. To our knowledge, it does not exist alternative offering the same possibilities. This model was reused in [48] to explore another verification approach based on TRECANets. TRECANets are derived from Petri nets and allow recursion. They make it easy to express a minimum and maximum duration for care and to model successions and repetitions.

\subsection{Scheduling and routing}

The approach we have proposed allows to generate a daily scheduling for executing the interventions of the whole patients managed by a home care structure. This process allows to express patients' preferences with multiple time-windows and give good results on the respect of patients' preference. Since the project has finished, further works have been developed with multiple time windows $[49,50]$ and confirm the interest for these problems.

The experimentation phase was able to identify some limits of this work concerning the configuration of the optimization process, the stability of the plans and the interdependent services scheduling. In this study, we have assumed that the decision maker (the planner) is able to provide realistic weights for each criterion of the objective function. This task can be difficult and the values selected have an important influence on the results of optimization process. An interesting complementary work would be to propose a methodological approach for helping decision makers in this task.
Another setback identified concerns the difficulty of ensuring a stability of the hours of intervention for a patient over time. This functionality which was not satisfied in this first development could be used to implement re-scheduling approach during the tour. Indeed, when a problem occurs during the execution of the plan (new patient, a supplementary intervention, unavailability of a worker, etc.), it is very important that the adaptation of the plan in real time does not modify too much the planned interventions. Current works, developed in the project ANR SMART PLANNING, aim to take into account these events in the scheduling process in an anticipative way in order to generate robust schedule. Besides this, recent works have explored this way to model continuity of care with the definition of a criterion measuring the total number of different nurses that visit the same client during a planning horizon $[51,52]$.

Sometimes, for the execution of specific interventions (i.e. complex patients' manipulation, lifting over-weighted patients), it is necessary to have two or more workers in the same time at the patient' house. Taking this constraint into account requires synchronizing the schedule of two workers. Further works, like those of En-nahli et al. [53] and Mankowska et al. [35], integrate interventions synchronization mechanisms. For instance, En-nahli et al. [53] propose an approach based an Iterated Local Search (ILS) metaheuristic coupled with a variant of the Random Variable Neighborhood Descent method (RVND) which uses a random ordering of neighborhoods in local search phase (RVND-ILS algorithm) to solve this vehicle routing problem with time windows and synchronization constraints (VRPTWSyn).

In real world, the previous planning period influences the evaluation of some constraints (e.g. equilibrium workload, minimum and maximum number of consecutive working days) [54]. In our study, we focused on daily tour generating. So, it was not possible to take these objectives into account in optimization processing.

\subsection{Architecture of the platform}

We chose a process oriented development approach which corresponded to the process modeling we used to model activities. The development itself was organized around a relational database and involved the MYSQL, JPA, VAADIN technologies. Subsequently, we tested, still using a process oriented approach, a development organized around a NoSQL database with the MongoDB system [55]. MongoDB is a document oriented system. We have associated it with Web Services to take processes into account. A NoSQL document oriented system has advantages and disadvantages that are related to the types of applications. Designing the logical data model and implementing the physical model is generally simpler and more direct than with a relational system. The format of documents can easily be changed. But references between documents must be managed by the developer and a NoSQL system must only be used for applications with fairly simple reference schemes. In addition, transactional operations are not supported by MongoDB and, if necessary, a transaction management must be implemented. Fortunately, our application only involves simple cases for both references and transactions and it has appeared that a system such as MongoDB could bring greater ease of development and offer greater agility than a relational system. For some processes, and in particular scheduling, it appeared that users wish to define their own rules. In this perspective, a development paradigm associating processes and rules could be a direction to explore.

\subsection{Usages}

The experiments showed that the interfaces were appropriate for both types of actors and that the platform could provide 
effective assistance at several levels: specification of care plans, scheduling, tours piloting, monitoring care interventions. However the platform involves a significant change in habits and a more rigorous organization. It is at this level that acceptability arises. The resolution of the last minute hazards is more constraining than in a manual management. Greater flexibility should therefore be allowed to trigger definitive acceptance by users.

\section{Conclusion}

The objective of the project was to develop an interactive ICT platform to support home care services. It was a matter to favor communication among actors, coordination of activities and continuity of care. The platform is designed around three main processes: modeling care plans, planning visits and tours, monitoring homecare interventions. These three processes offer three complementary visions of the care plan: prescribed vision, planned vision, performed vision. The project introduced new scientific contributions. A DSL and a temporal model were proposed to formalize a care plan. This model is then used to automatically verify a care plan using a timed automaton approach. Various investigations were carried out on the planning of visits. Some of these contributions have been taken up by different research teams to be improved or to serve as a basis for further investigations. The proposals were tested in real conditions and welcomed by the users. They can be used as support for the realization of software components that can be integrated into commercialized systems.

\section{Human and animal rights}

The authors declare that the work described has been carried out in accordance with the Declaration of Helsinki of the World Medical Association revised in 2013 for experiments involving humans as well as in accordance with the EU Directive 2010/63/EU for animal experiments.

\section{Informed consent and patient details}

The authors declare that this report does not contain any personal information that could lead to the identification of the patient(s).

The authors declare that they obtained a written informed con sent from the patients and/or volunteers included in the article. The authors also confirm that the personal details of the patients and/or volunteers have been removed.

\section{Disclosure of interest}

The authors declare that they have no known competing financial or personal relationships that could be viewed as influencing the work reported in this paper.

\section{Funding}

This work has been supported by: The French National Agency for Research (ANR), within the TecSan framework and supported by the Cancer Bio Santé cluster.

\section{Author contributions}

All authors attest that they meet the current International Committee of Medical Journal Editors (ICMJE) criteria for Authorship.

\section{Acknowledgements}

The work presented here has been developed in the framework of project Plas'O'Soins, a nationwide project funded by the French National Agency for Research (ANR), within the TecSan framework (ANR-2010-TECS-016-08) and supported by the Cancer Bio Santé cluster. The authors would like to thank the end-user partners of Plas'O'Soins consortium: Albi Hospital, UMT, and CARMI Sud-Ouest for providing insight and expertise that greatly assisted the research and for allowing them to experiment the Plas'O'Soins platform in real situation. The authors would also like to thank the industrial partners: Almerys and CGx Systems for their contribution in specifying and developing phases of Plas'O'Soins platform.

\section{References}

[1] Lamine E, Tawil ARH, Bastide R, Pingaud H. An ontology-driven approach for the management of home healthcare process. In: Enterprise interoperability VI. Cham: Springer; 2014. p. 151-61.

[2] Lamine E, Tawil ARH, Bastide R, Pingaud H. Ontology-based workflow design for the coordination of homecare interventions. In: Working conference on virtual enterprises. Springer; 2014. p. 683-90.

[3] Mohammadzadeh N, Safdari R. Patient monitoring in mobile health: opportunities and challenges. Med Arch 2014;68:57.

[4] Darkins A, Ryan P, Kobb R, Foster L, Edmonson E, Wakefield B, et al. Care coordination/home telehealth: the systematic implementation of health informatics, home telehealth, and disease management to support the care of veteran patients with chronic conditions. Telemed E-Health 2008;14:1118-26.

[5] Kamei T. Information and communication technology for home care in the future. Jpn J Nurs Sci 2013;10:154-61.

[6] Wang F, Turner KJ. Towards personalised home care systems. In: Proceedings of the 1st international conference on PErvasive technologies related to assistive environments. ACM; 2008. p. 44.

[7] Bossen C, Christensen LR, Grönvall E, Vestergaard LS. Carecoor: augmenting the coordination of cooperative home care work. Int J Med Inform 2013;82:e189-99.

[8] Paganelli F, Giuli D. An ontology-based system for context-aware and configurable services to support home-based continuous care. IEEE Trans Inf Technol Biomed 2011:15:324-33.

[9] Lasierra N, Alesanco A, Guillén S, García J. A three stage ontology-driven solution to provide personalized care to chronic patients at home. J Biomed Inform 2013:46:516-29.

[10] Koutkias VG, Chouvarda I, Maglaveras N. A multiagent system enhancing homecare health services for chronic disease management. IEEE Trans Inf Technol Biomed 2005;9:528-37.

[11] Isern D, Moreno A, Sánchez D, Hajnal Á, Pedone G, Varga LZ. Agent-based execution of personalised home care treatments. Appl Intell 2011;34:155-80.

[12] Bricon-Souf N, Anceaux F, Bennani N, Dufresne E, Watbled L. A distributed coordination platform for home care: analysis, framework and prototype. Int J Med Inform 2005;74:809-25.

[13] Lamine E, Zefouni S, Bastide R, Pingaud H. A system architecture supporting the agile coordination of homecare services. In: Collaborative networks for a sustainable world; 2010. p. 227-34.

[14] Next Step in Care - A Programm of United Hospital Fund. A family caregiver's planner for care at home. http://www.nextstepincare.org/Caregiver_ Home/Care_Planner/, 2008.

[15] Fédération nationale des établissement d'hospitalisation à domicile. Livre blanc des systèmes d'information en hospitalisation à domicile. 1st edition. FNEHAD; 2009.

[16] Monsen K, Foster D, Gomez T, Poulsen J, Mast J, Westra B, et al. Evidencebased standardized care plans for use internationally to improve home care practice and population health. In: Applied clinical informatics - Schattauer; 2011. p. 373-80.

[17] Riaño D, Real F, Campana F, Ercolani S, Annicchiarico R. An ontology for the care of the elder at home. In: Proceedings of the 12th conference on artificial intelligence in medicine: artificial intelligence in medicine. Berlin, Heidelberg: Springer-Verlag; 2009. p. 235-9.

[18] Hägglund $M$, Chen R, Koch S. Modeling shared care plans using CONTsys and openHR to support shared homecare of the elderly. J Am Med Inform Assoc 2011;18:66-9. https://doi.org/10.1136/jamia.2009.000216.

[19] Hindle T, Hindle A, Spollen M. Resource allocation modelling for homebased health and social care services in areas having differential population density levels: a case study in Northern Ireland. Health Serv Manag Res 2000;13:164-9. https://doi.org/10.1177/095148480001300304.

[20] Hindle T, Hindle G, Spollen M. Travel-related costs of population dispersion in the provision of domiciliary care to the elderly: a case study in English local authorities. Health Serv Manag Res 2009;22:27-32. https://doi.org/10.1258/ hsmr.2008.008012. 
[21] Ernst AT, Jiang H, Krishnamoorthy M, Owens B, Sier D. An annotated bibliography of personnel scheduling and rostering. Ann Oper Res 2004;127:21-144. https://doi.org/10.1023/B:ANOR.0000019087.46656.e2.

[22] Rinder M, Weckman G, Schwerha D, Snow A, Dreher P, Park N, et al. Healthcare scheduling by data mining: literature review and future directions. J Healthc Eng 2012;3:477-502. https://doi.org/10.1260/2040-2295.3.3.477.

[23] Moyaux T, Chaib-draa B, D’Amours S. Satisfaction distribuée de constraintes et son applicationa la génération d'un emploi du temps d'employés. In: Actes du 5e congrès international de génie industriel; 2003.

[24] Burke E, Cowling P, De Causmaecker P, Berghe GV. A memetic approach to the nurse rostering problem. Appl Intell 2001;15:199-214

[25] Meisels A, Schaerf A. Modelling and solving employee timetabling problems. Ann Math Artif Intell 2003;39:41-59. https://doi.org/10.1023/A: 1024460714760.

[26] Beddoe, G. Petrovic, S. Determining feature weights using a genetic algorithm in a case-based reasoning approach to personnel rostering, 2004.

[27] Chen JG, Yeung TW. Hybrid expert-system approach to nurse scheduling. Comput Nurs 1993;11:183-90.

[28] Yeung TW-K. Hybrid expert system approach to nurse scheduling. University of Houston; 1991.

[29] Bachouch RB. Pilotage opérationnel des structures d'hospitalisation à domicile. Ph.D. thesis, INSA de Lyon; 2010.

[30] Akjiratikarl C, Yenradee P, Drake PR. PSO-based algorithm for home care worker scheduling in the UK. Comput Ind Eng 2007;53:559-83. https://doi.org/10. 1016/j.cie.2007.06.002

[31] Vidal T, Crainic TG, Gendreau M, Prins C. A hybrid genetic algorithm with adaptive diversity management for a large class of vehicle routing problems with time-windows. Comput Oper Res 2013;40:475-89. https://doi.org/10.1016/j. cor.2012.07.018.

[32] Favaretto D, Moretti E, Pellegrini P. Ant colony system for a VRP with multiple time windows and multiple visits. J Interdiscip Math 2007;10:263-84. https:// doi.org/10.1080/09720502.2007.10700491.

[33] Bachouch RB, Guinet A, Hajri-Gabouj S. A decision-making tool for home health care nurses' planning. Supply Chain Forum Int J 2011;12:14-20. https://doi.org/ 10.1080/16258312.2011.11517250.

[34] Gayraud F, Deroussi L, Grangeon N, Norre S. A new mathematical formulation for the home health care problem. Proc Technol 2013;9:1041-7. https://doi.org/ 10.1016/j.protcy.2013.12.116.

[35] Mankowska DS, Meisel F, Bierwirth C. The home health care routing and scheduling problem with interdependent services. Health Care Manage Sci 2014;17:15-30. https://doi.org/10.1007/s10729-013-9243-1.

[36] Maya Duque PA, Castro M, Sörensen K, Goos P. Home care service planning. The case of Landelijke Thuiszorg. Eur J Oper Res 2015;243:292-301. https:// doi.org/10.1016/j.ejor.2014.11.008.

[37] Braekers K, Hartl RF, Parragh SN, Tricoire F. A bi-objective home care scheduling problem: analyzing the trade-off between costs and client inconvenience. Eur J Oper Res 2016;248:428-43. https://doi.org/10.1016/j.ejor.2015.07.028.

[38] Fikar C, Hirsch P. Home health care routing and scheduling: a review. Comput Oper Res 2017;77:86-95. https://doi.org/10.1016/j.cor.2016.07.019.
[39] Bajorek M, Nowak J. The role of a mobile device in a home monitoring healthcare system. In: 2011 federated conference on computer science and information systems (FedCSIS). IEEE; 2011. p. 371-4.

[40] Ventola CL. Mobile devices and apps for health care professionals: uses and benefits. Pharm Ther 2014;39:356.

[41] Gani K, Bouet M, Schneider M, Toumani F. Formal modeling and analysis of home care plans. In: 12th International conference on service oriented computing (ICSOC 2014); 2014.

[42] Bouet M, Gani K, Schneider M, Toumani F. A general model for specifying near periodic recurrent activities-application to home care activities. In: 2013 IEEE 15th international conference on E-health networking, applications \& services (Healthcom). IEEE; 2013. p. 207-11.

[43] Alur R, Dill DL. A theory of timed automata. Theor Comput Sci 1994:183-235.

[44] Cassez F, Roux O-H. Structural translation from time Petri nets to timed automata. Electron Notes Theor Comput Science 2005;128(6):145-60.

[45] Gani K. Using timed automata formalism for modeling and analyzing home care plans. Ph.D. thesis, Universite Blaise Pascal Clermont-Ferrand II; 2015.

[46] Yannakakis M, Lee D. An efficient algorithm for minimizing real-time transition systems. In: Proceedings of the 5th international conference on computer aided verification. London, UK: Springer-Verlag; 1993. p. 210-24.

[47] Gourc D, Marmier F, Gaborit P. An approach based on tabu search technique for solving a multi time window home healthcare scheduling problem. In: MOSIM 2014, 10ème conférence francophone de modélisation, optimisation et simulation; 2014.

[48] Barkaoui K, Hicheur A, Kheldoun A, Liu D. Modelling and analyzing home care plans using high-level Petri nets. In: 2016 13th international workshop on Discrete event systems (WODES). IEEE; 2016. p. 284-90.

[49] Belhaiza S, Hansen P, Laporte G. A hybrid variable neighborhood tabu search heuristic for the vehicle routing problem with multiple time windows. Comput Oper Res 2014;52:269-81. https://doi.org/10.1016/j.cor.2013.08.010.

[50] Beheshti AK, Hejazi SR, Alinaghian M. The vehicle routing problem with multiple prioritized time windows: a case study. Comput Ind Eng 2015;90:402-13. https://doi.org/10.1016/j.cie.2015.10.005.

[51] Bowers J, Cheyne H, Mould G, Page M. Continuity of care in community midwifery. Health Care Manage Sci 2015;18:195-204. https://doi.org/10.1007/ s10729-014-9285-z.

[52] Milburn AB, Spicer J. Multi-objective home health nurse routing with remote monitoring devices. Int J Plan Sched 2013;1:242-63. https://doi.org/10.1504/ IJPS.2013.059677.

[53] En-nahli L, Afifi S, Allaoui H, Nouaouri I. Local search analysis for a vehicle routing problem with synchronization and time windows constraints in home health care services. IFAC-PapersOnLine 2016;49:1210-5. https://doi.org/ 10.1016/j.ifacol.2016.07.674.

[54] Burke E, De Causmaecker P, Petrovic S, Berghe GV. Variable neighborhood search for nurse rostering problems. In: Metaheuristics: computer decisionmaking, applied optimization. Boston, MA: Springer; 2003. p. 153-72.

[55] Bouet M, Schneider M. A NoSQL-based framework for managing home services. Open J Inf Syst (OJIS) 2016;3:1-28. 